\title{
Investigating Attitude And Motivation Of Iranian University Learners Toward English As A Foreign Language
}

Sima Sayadian, Islamic Azad University,Iran Anita Lashkarian, Islamic Azad University, Iran

\begin{abstract}
This Paper discusses the attitudes and motivation Iranian learners have toward learning EFL at their university level. Although research of a similar nature has been done in other countries, the present study complements others by following 500 university learners and it provides another avenue for examining the language situation in Iran. To achieve this goal, Gardner's socioeducational model and the significance of motivation as a contributing factor in second/foreign language (SL/FL) learning are taken into consideration.
\end{abstract}

The questions to be addressed in this paper are:

- $\quad$ What are the university learners' attitudes for learning EFL?

- $\quad$ What are the university learners' motivations for learning EFL?

- $\quad$ Does gender influence attitudes of Iranian learners for learning English as a foreign language?

- $\quad$ Does gender influence motivation of Iranian learners for learning English as a foreign language?

- $\quad$ Does a major course of the study influence attitudes of Iranian learners for learning English as a foreign language?

- $\quad$ Does major course of the study influence motivation of Iranian learners for learning English as a foreign language?

The investigation also demonstrates that Iranian learners learn English for 'instrumental' reasons and it concludes that 'integrative motivation' is the dominant motivational orientation for the Iranian learners to learn English as EFL. This study will possibly provide additional insights in better identifying the existing motivational challenges and in taking a more realistic perspective about the English Language Teaching (ELT) situation in the country. Finally, some recommendations on future directions for this research area in Iran have been highlighted.

Keywords: English as a Foreign Language, Attitude, Motivation, Language Learning.

If we value independence and if we are disturbed by the growing conformity of knowledge, of values, of attitudes, which our present system induces, then we may wish to set up conditions of learning which make for uniqueness, self-direction, and self-initiated learning. (Carl Rogers)

\section{INTRODUCTION AND BACKGROUND OF THE STUDY}

iven that English is the language of international communication, providing Iranian learners, who are facing rapid internationalization with appropriate proficiency in English, is a pressing task for teachers. Most Iranian learners have their only real contact with EFL in schools and, as a result, EFL is more likely to be an academic exercise conducted in response to external pressure than a normal and accustomed extension of the need to communicate. In other words, many learners who have not attended extracurricular English 
classes at English language institutes, even after being instructed in English for a period 6 to 10 years, still cannot comprehend or compose many English sentences and fail to read, write or speak with proper fluency, while those taking extra English classes seem to fair pretty well, perhaps due to the simple assumption that the latter are supposed to be more motivated.

The homogeneous monolingual society of Iran is not a favorable environment for learning English. This can be expected to impact learners' motivations. In the climate described above, where English-language education in Iran is crucially important and facing an urgent need for reform, considering the attitudes and motivation of these learners is essential.

Research over the last three decades has consistently demonstrated that achievement in a second/foreign language is related to measures of attitudes and motivation (Clement, Gardner, and Smythe, 1980; Gardner and Lambert, 1972; Gardner and Smythe, 1981; Gliksman, 1981; Naiman et al., 1978; Oxford \& Shearin, 1994; Ushioda, 2001; and Dornyei, 2001). Teachers need to be aware of the different types of motivational orientation (Skehan, 2003) and of the importance of high quality feedback in helping to boost or maintain motivation. Awareness of motivation and attitudes toward language and language variations have been investigated widely by native speakers, language teachers and learners (cf. Trudgill, 2002; Barbour, 2000; James, 1996) or even ESL researchers Manfred Wu Man-Fat (2004).

Gardner \& Lambert (1972) define motivation as the second language learner's overall goal and orientation and attitude as the learner's persistence in striving to attain the goal. However, motivation and attitude are not, thereby, clearly delineated from one another in that the learners' motivations for language study would be determined by their attitudes and readiness to identify and by their orientation to the whole process of learning a foreign language.

Some researchers (like Gardner, 1985; Gardner \& Tremblay, 1994) explained that motivation differs from orientation because a learner might demonstrate a particular orientation, but not be highly motivated to achieve that goal. Moreover, although researchers have used the same terminology (i.e., instrumental and integrative) for motivation as well as for orientation, motivation reflects the power to attain the goal reflected in the orientation. This power, Gardner suggested, stems from the desire to attain the goal, positive attitudes toward learning the language, and effortful behavior. The integrative motive (or integrative motivation) is the high level of drive on the part of the individual to acquire the language of a valued L2 group in order to facilitate communication with that group (Gardner, 1985). In 1974, working with another Canadian researcher, Pat Smythe, Gardner published the Attitude/Motivation Test Battery (AMTB). It consists of a series of Likert-scale items, such as "I would like to know more French-Canadians", to which learners indicated one of several responses, including "strongly disagree" to "strongly agree". According to Gardner's (1985) socio-educational model, motivation is an internal attribute of the individual that can be influenced by external forces. Most studies of the model have focused on integrative motivation as its central feature and key individual difference variable (see Gardner, 1996 and Gardner \& Masgoret, 2003).

Gardner and Lambert identify two types of motivation - instrumental motivation, or 'a desire to gain social recognition or economic advantages through knowledge of a foreign language', and integrative motivation, or 'a desire to be a representative member of the other language community' $(1972, \mathrm{p}$. 14). They found that learners with integrative motivation were more successful in learning a second/foreign language than those with instrumental motivation.

Pavlenko (2002) even goes so far as to assert that integrative motivation is a more powerful force than instrumental motivation because an absence of integrative motivation can outweigh instrumental motivation that does exist, halting or severely retarding language learning. This assumption explains very well what MacIntyre (2002) refers to as the 'seemingly contradictory behavior' of people whose low level of effort does not match their professed instrumental motivation. It seems that even when learners know they need to - or should - learn a language (instrumental motivation), if they don't truly want to do so because they have no respect for or appreciation of the target culture (lack of integrative motivation), they are likely to fail. 
Gass and Selinker (2001) agree that "it makes sense that individuals who are motivated will learn another language faster and to a great degree. Furthermore, numerous studies have provided statistical evidence that indicates motivation is a predictor of the language learning success". They then proceed to validate attitude as one cause of motivation.

Brown (2000) makes the point that both integrative and instrumental motivations are not necessarily mutually exclusive. Learners rarely select one form of motivation when learning a second/foreign language, but rather a combination of both orientations.

\section{STATEMENT OF PROBLEM}

At all universities in Iran, English is taught to non-English major students as a compulsory subject, usually in the form of one or two classes a week of so-called 'General English' (3 credits), which is not necessarily related to the learners' majors. In the third and fourth year, learners (other than those majoring in English) usually have no English classes. They endure English classes only to accumulate enough credits to graduate. Learners feel that the content of university courses is largely irrelevant to their future job and that graduating after four years of minimum effort, rather than learning, is the most appropriate goal. The current perception of Iranian university learners - in society at large, among their teachers, and among learners themselves - is of a largely unmotivated group enjoying four years of leisure between the examination hell of high school and the rigors of work or restrictions of marriage, depending on the gender of the learner.

This paper discusses the attitudes and motivation Iranian learners have toward learning EFL at their university level. Although research of a similar nature has been done in other countries, the present study complements others by following 500 university students, which provides another avenue for examining the language situation in Iran. To achieve the goal, Gardner's socio-educational model and the significance of motivation as a contributing factor in second/foreign language (SL/FL) learning is taken into consideration.

\section{PURPOSE OF THE STUDY}

In order to examine language learning in the Iranian context, especially universities, it is necessary to explore a number of factors which contribute to the way in which English education is conducted in Iran.

For the purpose of this paper, attitude refers to a learner's ability as a learner, attitude toward the classroom setting, and the language learners' feelings toward and opinions about the target culture and the target language. Attitude is likewise important because it can be a reason for that motivation, or lack thereof.

The present paper tries to identify the societal factors and psychological factors that motivate learners to better perform in EFL and to postulate a theoretical model subsuming these socio-psychological variables to explain and predict the performance in EFL of Iranian learners.

\section{SIGNIFICANCE OF THE STUDY}

Much recent research has related this area of foreign language learning more specifically to formal instruction. Masgoret et al. (2003) and Dornyei (2003) declare that attitudes and motivation are key factors that influence the rate and success of second/foreign language learning in the classroom. Anderson (2001) even argues that attitudes shaped by this social context are the most important factors in determining the success of formal classroom language instruction.

The learners in this study, like many EFL learners throughout the world, lacked enthusiasm for the activities used, showing little or no interest in participating, unless forced by the teachers. Although it was felt that little could be done to influence the effect of learners' external sources of motivation (or lack of it), it seemed that if their enjoyment of and interest in English classes on an activity-by-activity basis could be increased, better conditions for successful learning could be created. In addition, it was expected that by finding ways of making classes more engaging, the learners' general attitudes toward English as a school subject would improve, and further, long-term motivational benefits would therefore be gained. Moreover, the teachers' professional understanding would benefit as they would gain greater insight into the processes involved in motivating reluctant 
learners. There is a hope that in reporting the project, other teachers would gain ideas and insights into how to tackle similar problems in their own classrooms.

\section{RESEARCH QUESTIONS}

The questions addressed in this paper are:

- What are Iranian university students' attitudes for learning EFL?

- What are Iranian university students' motivations for learning EFL?

- Does gender influence attitudes of Iranian university students for learning English as a foreign language?

- Does gender influence motivation of Iranian university students for learning English as a foreign language?

- Does major course of the study influence attitudes of Iranian university students for learning English as a foreign language?

- Does a major course of the study influence motivations of Iranian university students for learning English as a foreign language?

\section{INSTRUMENT}

In this study, the revised Persian version of AMTB was applied to identify Iranian university students' attitudes and motivation toward learning English as a foreign language. The questionnaire comprised of two main sets of questions that involve assessments of attitudinal and motivational variables associated with second/foreign language learning. The first set consists of a total of 53 questions divided into seven categories. The first category is comprised of ten questions designed to measure the learners' interests in foreign language (IFL Questions 1-10) and the second category consists of ten questions designed to measure attitudes toward English speakers (AES Questions 11-20). The third category also consists of ten questions developed to measure attitudes toward learning English (ALE Questions 21-30), while the fourth category includes four questions provided to measure integrative Orientation (INTO Questions 31-34). The fifth category contains four questions to measure instrumental orientation (INSTO Questions 35-38) and the sixth category consists of five questions measuring English class anxiety (ECA Questions 39-43). The last category comprises of ten questions to measure parental encouragement (PE: Questions 44-53). The next set of questions were aimed to measure motivation, which contained three categories designed to measure three primary concepts in the socio-educational model: 1) motivational intensity (Questions 54-63), Desire to learn EFL (Questions 64-73), and orientation index (Question 74).

Table 1 illustrates section A of AMTB measuring Attitudes with its items 1-53.

Table 1: Section A of AMTB Measuring Attitudes with its Items

\begin{tabular}{|c|c|}
\hline Question No. & Category Name \\
\hline $1-10$ & Interest in Foreign Language (IFL) \\
\hline $11-20$ & Attitudes toward English Speakers (AES) \\
\hline $21-30$ & Attitudes toward learning English (ALE) \\
\hline $31-34$ & Integrative Orientation (INTO) \\
\hline $35-38$ & (Instrumental Orientation (INSTO) \\
\hline $39-43$ & English Class Anxiety (ECA) \\
\hline $44-53$ & Parental Encouragement (PE) \\
\hline
\end{tabular}

Table 2 illustrates section B of AMTB, which analyzes language learners' motivations in learning EFL for 20 items (54-74) on a multiple-choice basis.

Table 2: Section B of AMTB Measuring Motivation with its Items

\begin{tabular}{|c|c|}
\hline Question No. & Category Name \\
\hline $54-63$ & Motivational Intensity \\
\hline $64-73$ & Desire to Learn English \\
\hline 74 & Orientation Index \\
\hline
\end{tabular}




\section{PARTICIPANTS}

For the study, 537 learners (210 male and 327 female) between the ages of 19 and 24 were randomly selected from Yazd University, Iran (Table 3). In other words, almost 10\% of the students' strength of Yazd University was considered. It is noteworthy that of the present student population in Iranian universities, female learners exceed in number as compared to male counterparts. The reason for selecting this university is mainly twofold: first, since we have been associated with the institution, as faculty members in English Language Teaching since the last 25 years, this not only gives us a first-hand experience of the learners' psychology and attitudes toward the learning of English, but also makes our stance more credible, while giving us an opportunity to have an access to the learners easily and comfortably. The respondents were Farsi speakers learning EFL and came from different academic majors. It should be clarified that the selection of non-English majors to become the participants of the study was based on the fact that they leaned more toward instrumental motivation, learning English for utilitarian purposes, for example, gaining a proficiency in English as an essential requirement for pursuing higher studies.

Table 3: Sample Population

\begin{tabular}{|c|c|c|}
\hline Gender & Number & Percentage \\
\hline Female & 327 & 60.89 \\
\hline Male & 210 & 39.10 \\
\hline Total & 537 & 100 \\
\hline
\end{tabular}

\section{METHODOLOGY}

The present analysis focuses on studies conducted by Gardner and associates using the Attitude Motivation Test Battery (AMTB) and related measures within the paradigm of the socio-educational model of second/foreign language acquisition (Gardner, 1985a).

With the help of the Persian version of Gardner's AMTB questionnaire, the data were obtained and processed. ANOVA was applied to check for analyzing different categories of motivation while the t-test was applied to check for the frequencies of subcategories for attitude with which the categories occurred.

For practical reasons (a large number of learners for a limited time), the methods chosen for data collection consisted of self-report questionnaires administered randomly to non-English major learners of Yazd University. The questionnaire, based on Gardner's Attitude/Motivation Test Battery or AMTB (Gardner 1985, pp. 177-84, cited in Williams and Burden, 1997), was designed to elicit information regarding each learner's integrative motivation, instrumental motivation, and attitude toward language learning.

The participants were grouped on the basis of formal division of courses at Yazd University (Table 4).

Table 4: Total Number of Participants from Different Faculties

\begin{tabular}{|c|l|c|c|}
\hline Faculty Code & \multicolumn{1}{|c|}{ Faculty including Different Departments } & No. of Learners & Percentage \\
\hline 1 & $\begin{array}{l}\text { Humanities: (Accounting, Commercial Management, Economics, } \\
\text { Islamic Laws, Geography, History, Industrial Management Library } \\
\text { Science, Political Science, Psychology, Social Science) }\end{array}$ & 257 & 47.85 \\
\hline 2 & Literature: (Persian and Arabic) & 33 & 0.14 \\
\hline 3 & Sciences: (Biology, Chemistry, Physics) & 43 & 8 \\
\hline 4 & Mathematics and Statistics: & 52 & 9.68 \\
\hline 5 & $\begin{array}{l}\text { Engineering: (Civil, Computer, Electronics, Industrial Eng. } \\
\text { Mechanical Eng., Metallurgy, Textile Eng.) }\end{array}$ & 139 & 25.88 \\
\hline 6 & Natural Resources: & 537 & 2.42 \\
\hline Total & & 13 & 100 \\
\hline
\end{tabular}




\section{DATA ANALYSIS AND DISCUSSION}

Based on the data obtained from the questionnaire (AMTB), EFL learners' attitudes were analyzed. With reference to a six-point Likert scale of AMTB, scales 0-2 (from strongly disagree to disagree to slightly disagree) were considered to show a low attitude, whereas scales 3-5 (from agree to slightly agree to strongly agree) indicated a high attitude toward learning English. Furthermore, for a better understanding of attitudes, the EFL learners were also analyzed on the basis of their gender. The main aim was to observe whether gender plays a significant role among Iranian EFL learners.

Table 5: Percentage Distribution of Gender and Degree of Attitudes for Items Measuring Interest in Foreign Language (IFL Questions 1-10)

\begin{tabular}{|c|c|c|c|c|c|}
\hline Gender & Low Attitude & Percentage & High Attitude & Percentage & Total \\
\hline Female & 13 & 3.97 & 314 & 96.02 & 327 \\
\hline Male & 14 & 6.66 & 196 & 93.33 & 210 \\
\hline Total & 27 & 5.02 & 510 & 94.97 & 537 \\
\hline
\end{tabular}

The above table indicates that male and female learners of non- English majors of Yazd University showed a high attitude toward EFL with respect to interest in foreign language.

Moreover, both male and female learners showed a tendency toward low attitude $(60 \%$ and $50 \%$, respectively) with respect to their attitudes toward English speakers, while both male and female participants were highly oriented $(91.86 \%$ and $89.87 \%$, respectively ) with respect to their attitude toward learning English. As far as integrative orientation is concerned, both male and female participants proved high percentages $(65.86 \%$ and $66.76 \%$, respectively) and similarly, both male and female groups were highly instrumentally oriented (91.38\% and $92.92 \%$, respectively). However, male and female subjects differed slightly in the case of English class anxiety. The male group indicated lower attitude (51.69\%) compared to the female students (47.82\%), meaning there is not much difference between the attitudes, yet it can be stated that male learners showed a tendency toward low attitude with respect to English class anxiety. Finally, considering parental encouragement, both male and female participants showed a rather high attitude $(69.30 \%$ and $72.98 \%$, respectively).

As a general illustration of percentage distribution of all the faculties and degree of attitudes, it was apparent that students of Natural Resources Faculty, in general, revealed lower attitudes toward EFL (84.61\%) as compared to the students in Engineering Faculty who displayed perfectly high attitudes toward EFL (100\%).

The following descriptive analysis relating to seven items is observed:

Table 6: ANOVA Analysis of Learners' Attitudes with Respect to their Faculties

\begin{tabular}{|c|c|c|}
\hline No. & Items Measuring Attitudes & Mean Square \\
\hline 1 & IFL(1-10) & 0.020 \\
\hline 2 & AES(11-20) & 0.131 \\
\hline 3 & ALE $(21-30)$ & 0.426 \\
\hline 4 & INTO $(31-34)$ & 0.461 \\
\hline 5 & INSTO $(35-38)$ & 0.277 \\
\hline 6 & ECA $(39-43)$ & 0.362 \\
\hline 7 & PE $(44-53)$ & 0.283 \\
\hline
\end{tabular}

As presented in Table 6, the learners' attitudes toward learning English proved to be insignificant in all the subcategories of attitudes, except the first category, which is interest in foreign language (IFL) with a value of 0.020 .

Table 7 presents data obtained from ANOVA analysis of learners' attitudes with respect to their gender. 
Table 7: ANOVA Analysis of Learners' Attitudes with Respect to their Gender

\begin{tabular}{|c|c|c|}
\hline No. & Items Measuring Attitudes & Mean Square \\
\hline 1 & IFL (1-10) & 0.046 \\
\hline 2 & AES (11-20) & 0.810 \\
\hline 3 & ALE (21-30) & 0.090 \\
\hline 4 & INRO (31-34) & 0.144 \\
\hline 5 & INSTO (35-38) & 0.723 \\
\hline 6 & ECA (39-43) & 0.164 \\
\hline 7 & PE ( 44- 53) & 0.288 \\
\hline
\end{tabular}

From the data analyzed, it can be assumed that interest in foreign language (IFL) seems to show a significant difference as compared to the other six items. In the other words, female learners showed to be different from male learners only in their interest in foreign language.

Having considered section A of the questionnaire, it is necessary to see the data and its analysis in relation to section $\mathrm{B}$ of the questionnaire, which focuses on learners' motivations toward EFL.

Table 8 analyzes language learners' motivations in learning EFL for 20 items (54-74) on a multiple-choice basis.

Table 8: T-Test Results of Learners' Motivation with Respect to Major

\begin{tabular}{|c|c|c|}
\hline No. & Motivation & Mean Square \\
\hline 1 & Motivational Intensity & 0.162 \\
\hline 2 & Desire to learn English & 0.728 \\
\hline 3 & Orientation Index & 0.079 \\
\hline
\end{tabular}

As shown in the above table, there was no significant relationship between the categories in relation to the learners' majors.

Table 9 presents the T-test results of learners' motivations with respect to gender.

Table 9: T-Test Results of Learners' Motivations with Respect to Gender

\begin{tabular}{|c|c|c|}
\hline No. & Motivation & Mean Square \\
\hline 1 & Motivational Intensity & 0.022 \\
\hline 2 & Desire to learn English & 0.110 \\
\hline 3 & Orientation Index & 0.167 \\
\hline
\end{tabular}

As indicated in the above table, motivational intensity seems to be significant with respect to gender. In other words, orientation index and desire to learn English do not play an active role in relation to gender.

Table 10 indicates the total percentage of instrumental and integrative orientation.

Table 10: Total Percentage of Instrumental and Integrative Orientation

\begin{tabular}{|c|c|}
\hline Orientation Index & Percentage \\
\hline Instrumental & $72.43 \%$ \\
\hline Integrative motivation & $16.75 \%$ \\
\hline Missing & $10.80 \%$ \\
\hline
\end{tabular}

Item number 74 of Section B, in relation to motivation of learners toward learning EFL, needs further analysis. Contrary to items relating to motivational intensity and desire to learn English of the questionnaire that 
was covered by three choices, item number 74 had four choices, two of which showed tendencies toward instrumental motivation and the other two tended to be an indication of integrative motivation. Our study demonstrates that Iranian EFL learners are instrumentally motivated. Of course, similar results have also been achieved by other researchers, especially Asians, confirming the idea that almost all foreign language learners might be instrumental-oriented rather than integrative-oriented.

Table 11 shows item number 74 of Section B of AMTB.

Table11: Instrumental/Integrative Orientation \& Gender

\begin{tabular}{|c|c|c|c|}
\hline \multirow{2}{*}{ Gender } & \multicolumn{2}{|c|}{$\mathbf{7 4}$} & \multirow{2}{*}{ Total } \\
\cline { 2 - 4 } & Integrative & Instrumental & \\
\hline Female & 248 & 51 & 299 \\
\hline Male & 141 & 38 & 180 \\
\hline Total & 389 & 89 & 479 \\
\hline
\end{tabular}

Our findings suggest the importance of interest in foreign language (IFL) as one of the significant factors for learners' attitudes in learning English as a foreign language at the university level.

What emerged clearly from the analyses is the fact that Iranian female learners at the university level reported slightly greater, both integrative and instrumental motivation, to learn English language than did their male counterparts.

Although similar gender differences have been reported previously (e.g., Baker, 1992; Burstall, 1975; Gardner, 1985; and Samimy \& Tabuse, 1992), the differences have not been nearly as enduring as in the present study.

We do not know whether the gender difference can be attributed to a type of socialization that predisposes females to have a positive attitude toward languages or to the fact that most of the teachers in the various foreign language programs are female. We are inclined to believe that the advantage of female learners in motivation to learn a new language has more to do with gender role modeling than with any female predisposition to learning languages.

Finally, parents, on the whole, demonstrated positive attitudes toward their children's foreign language study. This finding is encouraging because it was coupled with strong learner perceptions of parental involvement. Our findings suggest that language educators of EFL need to find ways to incorporate parents into the instruction of their children.

\section{CONCLUSION}

Those who have the power to make decisions about curriculum in the education system seem to have considered little about the effects of attitudes on second/foreign language learning, and therein perhaps lies the root of our troubles. Our learners' attitude problems are a result of the culture in which they have been raised - the same culture that molded those who are designing foreign language curriculum for our classrooms. In light of this information gap, those with an understanding of the problems and solutions associated with attitude and foreign language education, the authors included, have a responsibility to share it, not just in publications read by other researchers, but among the educators who should be using such knowledge in their classrooms and with administrators who can institute the curriculum changes that are called for so desperately.

Many studies have shown that integrative-oriented learners, in general, achieve higher proficiency levels than instrumental-oriented learners. Apart from raising Iranian learners' levels of integrative motivation, teachers can improve the contents, teaching methods, and classroom activities to raise learners' interests and motivations in language learning. Both Keller (1984, cited in Ellis, 1990) and McNamara (1973, cited in Ellis, 1999) suggest that increasing learners' participation is a good way to raise their interests in learning, which in turn increases 
motivation. Learners who are able to set their own goals and evaluate their own progress were found to be more motivated (Holec, 1987 and Dickinson, 1987). As the causal relationship between integrative motivation and classroom behaviors is unclear, encouraging positive classroom behaviors may be another option for teachers to enhance learners' positive attitudes, which in turn raises motivation (Cook, 2002). Oxford and Ehrman (1993) mention "teachers must do everything they can to heighten FL/SL learning motivation by ensuring that the materials and the tasks are communicative, non-threatening, exciting, relevant, appropriately challenging, capable of stimulating successful performance, and presented according to learners' needs to help reverse any negative attitudes that might harm learners' motivations". This is a good attitude teachers should develop.

Further, the study of English should become relevant to learners' lives by making explicit the goals of learning and also by enriching the content of the lesson with elements that help learners take an active part in the learning process. Learners need to feel, at the end of each lesson, that they have learned something useful which they can use right away. Many English learners develop a love and hate attitude toward English, and this is evident in the contradictory data of the present study.

English is sometimes thought of - rather naively - as a neutral medium of communication. This is not so. English, like every other language, brings with it cultural and political baggage that sometimes conflicts with the prevailing societal mentality. Thus, Pennycook (1994) urges us to take a broader socio-political view which does not "reduce questions of language to such psychological notion as instrumental and integrative motivation, but must account for the extent to which language is embedded in social, economic and political struggles". This attitude can be proceeded in a follow-up program.

The unique feature of the socio-educational model is that it proposes that motivation can be influenced by other variables, such as attitudes toward the learning situation and integrativeness, as well as integrative and instrumental orientations (see Gardner, 2000) and that consequently, they have an indirect effect on achievement.

\section{RECOMMENDATIONS FOR FURTHER RESEARCH}

The present findings describe the motivational propensities of Iranian learners in a monolingual context and have indicated that some orientations may be found more reliably in some contexts rather than in others. As with all studies, then, it is essential to replicate this study to determine the applicability of the theory to other contexts. Such replication would seem particularly important given recent discussions concerning the relevance of Iranian learners' conceptualizations of motivation.

In conclusion, this article has presented an analytical framework that can organize the orientations and suggest a mechanism to explain their importance for learners' efforts and achievements in the L2. It will be possible to explore the relations among this paradigm and other motivational constructs, such as the integrative orientation.

In response to the criticism of the shortcoming of Gardner's dualistic conception and the validity of Gardner's data to monolingual society, Green (1999) advocates the use of other frameworks in the study of language learning motivation, which may be applied by other researchers.

This project did not set out to inform the world of a way to motivate EFL learners around the globe, or even in Iran. This project was principally for us and our learners in English classes who took part in the study. The study has been invaluable for us and our future learners by giving us a glimpse of the power of research to improve any given classroom situation and providing us with the experience to make those improvements in our continuing career as teachers of EFL. In addition, we hope it has provided a source of encouragement and ideas for other would-be researchers/teachers. 


\section{AUTHOR INFORMATION}

Sima Sayadian - Holding a BA in "English Translation" and an MA in "Language Teaching" from Iran, she is currently pursuing her PhD in TESL at University Putra Malaysia. She has been teaching English at universities for the past ten years and has presented papers in several international conferences. Her research interests include Meaningful vs. Rote Learning, Learner Autonomy, Learning Strategies, Attitudes and Motivation, as well as Technology Adoption and Integration in Language Classes.

Dr. Anita Lashkarian was awarded a Ph.D. in English Literature in 1997 from Mumbai University, India. Since 1977, she has been a member of the faculty of Languages and Literature, Yazd University, Iran. She has a number of publications to her credit, both national and international. Her field of interests include Literary Theories and Criticism, Women's Studies, Gender Studies, and Cultural Studies. She has spent quite a bit of time exploring Victorian Period with special focus on the women writers.

\section{REFERENCES}

1. Anderson, N. J. (2001). Developing metacognitive skills in foreign language learners. : Selected Papers from the Tenth International Symposium on English Teaching, 1-7. Taipei: English Teachers' Association.

2. Baker, C. (1992). Attitudes and language. Clevedon: Multilingual Matters.

3. Barbour, S. (2000). Accent, dialect, and language: National differences in the evaluation of language variation. Sociolinguistica, 14, 5-10.

4. Brown, H.D. (2000). Principles of language learning and teaching (4th ed.). Englewood Cliffs NJ: Prentice-Hall.

5. Burstall, C. (1975), Factors affecting foreign-language learning: A consideration of some relevant research findings, Language Teaching and Linguistic Abstract, 8: 5-125.

6. Clément, R., Gardner, R. and Smythe, P.C. (1980), Social and individual factors in second language acquisition, Canadian Journal of Behavioural Science, 12, 293-302.

7. Cook, V., ed. (2002) Portraits of the L2 user. Clevedon, England: Multilingual Matters

8. Dickinson, L. (1987), Self-instruction in Language Learning, Cambridge: Cambridge University Press.

9. Dörnyei, Z. (2001) Motivational strategies in the language classroom. Cambridge: CUP.

10. Dörnyei, Z., ed. (2003) Attitudes, orientations, and motivations in language learning. Oxford: Blackwell.

11. Ellis, R. (1999), The Study of Second Language Acquisition, Oxford: Oxford University Press.

12. Gardner, R. C. (2001). Integrative motivation and second language acquisition. In Z. Dörnyei \& R. Schmidt (Eds.), Motivation and second language acquisition (pp. 1-19). Honolulu: University of Hawai'i Second Language Teaching and Curriculum Center.

13. Gardner, R. C., \& Tremblay, P.F. (1994). On motivation, research agendas, and theoretical frameworks. Modern Language Journal, 78, 359-368. [EJ 497 731]

14. Gardner, R.C. (1985). Social psychology and second language learning: The role of attitudes and motivation. London: Edward Arnold.

15. Gardner, R.C. (1996), Motivation and second language acquisition: perspectives, Journal of the CAAL, 18(2): $19-42$.

16. Gardner, R.C. and Smythe, P.C. (1981), On the development of the attitude/motivation test battery, Canadian Modern Language Review, 37, 510-525.

17. Gardner, R.C., \& Lambert, W.E. (1972). Attitudes and motivation : Second language learning. Newbury House.

18. Gass, S., \& Selinker, L. (2001). Second language acquisition: An introductory course. Mahwah, NJ: Lawrence Erlbaum Associates, Inc., Publishers.

19. Gliksman, L. Gardner, R. and Smythe, P. (1982), The role of integrative motivation on students' participation in the French classroom, Canadian Modern Language Review, 38: 625-47.

20. Green, C.F. (1999), Categorising motivational drives in second language acquisition, Language, Culture and Curriculum, 12(3), 265-279.

21. Holec, H. (1987), The learner as manager: managing learning or managing to learn? In Wenden and Rubin (eds.).

22. James, C. (1996). A cross-linguistic approach to language awareness. Language Awareness, 5(3-4), 138-48. 
23. Keller, J. (1984), Motivational design of instruction, In Reigeluth (ed.).

24. Macintyre Et Al., 2002 P. Macintyre, S. Baker, R. Clément And L. Donovan, Sex And Age Effects On Willingness To Communicate, Anxiety, Perceived Competence, And L2 Motivation Among Junior High School French Immersion Students, Language Learning 52 (2002), Pp. 537-564. View Record In Scopus | Cited By In Scopus (18)

25. Masgoret, A. M., \& Gardner, R. C. (2003). Attitudes, motivation, and second language learning. Language Learning, 53, 123-163.

26. Masgoret, A., Bernaus, M., \& Gardner, R.C. (2001). Examining the role of attitudes and motivation outside of the formal classroom: a test of the mini-AMTB for children. In Z. Dörnyei and R. Schmidt (Eds.) Motivation and second language acquisition. (Technical Report \#23, pp. 281-295). Honolulu: University of Hawaii,Second Language Teaching and Curriculum Center

27. McNamara, J. (1973), Nurseries, streets and classrooms: some comparisons and deductions, Modern Language Journal, 57: 250-55.

28. Naiman, N., Fröhlich, M., Stern, H., and Todesco, A. (1978), The Good Language Learner. Research in Education Series No. 7, Toronto: The Ontario Institute for Studies in Education.

29. Oxford, R. and Ehrman, M. (1993), Second Language Research on Individual Differences, Annual Review of Applied Linguistics, 13: 188-205.

30. Oxford, R., \& Shearin, J. (1994). Language learning motivation: Expanding the theoretical framework. Modern Language Journal, 78, 12-28.

31. Pavlenko, A. (2002). Poststructuralist approaches to the study of social factors in second language learning and use. Chapter 11 in V. Cook (Ed.) Portraits of the L2 user. (pp. 277-304). Clevedon, England Multilingual Matters, Ltd.

32. Pennycook, A (1994). The Cultural Politics Of English As An International Language. Longman.

33. Samimy K. K. \& Tabuse, M. (1992). Affective variables and a less commonly taught language: A study in beginning Japanese classes. Language Learning, 42, 377-398.

34. Trudgill, P. (2002). Sociolinguistic variation and change. Washington, D.C.: Georgetown UP.

35. Ushioda, E. (2001) 'Language learning at university: exploring the role of motivational thinking' In: Z. Dörnyei \& R. Schmidt (eds.) Motivation and second language learning (pp. 91-124). Honolulu, HI: University of Hawaii Press. 
NOTES 